\title{
Aplikasi Pengolahan Data Kependudukan Industri 4.0 Berbasis Web
}

\author{
Siti Maesaroh* ${ }^{1}$, Ita Erliyani ${ }^{2}$, Yosi Fitria Ningsih ${ }^{3}$ \\ ${ }_{1,2,3}$ Program Studi Sistem Informasi Universitas Raharja \\ "1 siti.maesaroh@ raharja.info, ${ }^{2}$ ita.erliyani@ raharja.info, ${ }^{3}$ yosi.fitria@ raharja.info
}

\begin{abstract}
The term Industry 4.0 was born from the idea of a fourth industrial revolution. To realize Industry 4.0 academic involvement is needed in the form of research. Currently Industry 4.0 uses conventional information systems, namely recording population data in a master book that has been provided, then recapitulated to make population reports. The system that runs at the Kebon Besar Kelurahan office in Batu ceper Subdistrict currently still has many shortcomings, including requiring a long time in the process of finding data, as well as in the process of making reports. The purpose of this study is to produce a faster and more accurate population data management information system. This research uses data collection methods carried out by observation, literature study and interviews. The results of this study are to facilitate the people in charge of the process of managing population data, assisting in the process of inputting data, searching data, and population reports.
\end{abstract}

Key words: Industri 4.0, Information System, Logging Population

\begin{abstract}
Abstrak
Istilah Industri 4.0 lahir dari ide tentang revolusi industri keempat. Untuk mewujudkan Industri 4.0 keterlibatan akademik diperlukan dalam bentuk penelitian. Saat ini industri 4.0 menggunakan sistem informasi secara konvensional yaitu pencatatan data penduduk pada sebuah buku induk yang telah disediakan, kemudian di rekap kembali untuk membuat laporan penduduk. Sistem yang berjalan pada kantor Kelurahan Kebon Besar Kecamatan Batuceper saat ini masih mempunyai banyak kekurangan diantaranya membutuhkan waktu yang lama dalam proses pencarian data, maupun dalam proses pembuatan laporan. Tujuan penelitian ini untuk menghasilkan sistem informasi pengelolaan data penduduk yang lebih cepat dan akurat. Penelitian ini menggunakan metode pengumpulan data dilakukan dengan cara observasi, studi pustaka dan wawancara. Hasil dari penelitian ini yaitu untuk memudahkan orang yang bertugas dalam proses pengelolaan data penduduk, membantu dalam proses penginputan data, pencarian data, dan laporan penduduk.
\end{abstract}

Kata kunci: Industri 4.0, Sistem Informasi, Pendataan Penduduk

\section{Pendahuluan}

Perkembangan teknologi khususnya di bidang informasi dan komunikasi dari tahun ke tahun berperan penting bagi kehidupan manusia. Teknologi informasi sudah menjadi topik utama dalam kegiatan bisnis dunia. Pemanfaatan menggunakan teknologi dalam dunia bisnis dapat meningkatkan nilai bisnis perusahaan. Semakin besar minat pelaku bisnis dalam mengembangkan usaha mereka dengan teknologi, semakin besar pula minat pekerjaan dalam bidang teknologi informasi. Dunia saat ini sedang menghadapi perubahan industri ke-4 atau yang dikenal dengan Industri 4.0. Istilah Industri 4.0 pertama kali muncul di Jerman saat diadakannya Hannover Fair 2011 (Kagermann dkk, 2011). Berdasarkan analisis Mckinsey Global Institute, Industri 4.0 memberikan dampak yang sangat besar dan luas, terutama pada sektor lapangan kerja, di mana robot dan mesin akan menghilangkan banyak lapangan kerja di 
dunia. Dengan kemajuan teknologi saat ini semua orang berusaha untuk membuat sistem yang mudah diakses dan mempunyai pengaruh positif dalam setiap kegiatan.

Sistem informasi yang baik dan berkualitas merupakan hal utama yang sangat diperhatikan dan menjadi suatu tujuan untuk dicapai guna memberikan kepuasan dan kemudahan dalam memperoleh informasi yang dibutuhkan bagi manusia untuk menunjang keputusan. Sistem informasi dapat mencapai keunggulan kompetitif pada tiga tingkatan: strategis, taktis, dan operasional. Ketika ketiga tingkatan diatas bekerja untuk mencapai tujuan yang sama, maka perusahaan akan dapat meraih potensi keuntungan yang paling besar. Sistem Informasi pengolahan data kependudukan adalah salah satu sarana yang mempermudah petugas pencatat data penduduk untuk mendata seluruh penduduk tersebut. Selain itu sistem ini juga akan lebih mempermudah masyarakat dalam hal kebutuhan pelayanan surat - surat. Sistem informasi dapat diterapkan pada instansi atau perusahaan untuk mengolah data dan menyajikan informasi atau laporan-laporan sesuai dengan kebutuhan pengguna secara cepat, tepat, dan akurat.

\section{PERMASALAHAN}

Industri 4.0 dalam menangani pengolahan data penduduk dan pembuatan surat keterangan status atau surat menyurat masih sangat sederhana hanya menggunakan pencatatan secara manual dan laporan datanya menggunakan pembukuan atau arsip - arsip. Untuk dapat meningkatkan pengolahan data penduduk beserta laporannya, maka harus merubah sistem yang lama (manual) menjadi sistem yang terkomputerisasi dimana komputer sebagai alat bantu dalam menyelesaikan tugas - tugas yang berkaitan dengan pendataan penduduk, sehingga setiap pekerjaan dapat diselesaikan dengan efektif dan efisien.

\section{Metode Penelitian}

\section{Metode Pengumpulan Data}

\section{Observasi}

Melakukan kunjungan dan pengamatan langsung ke Kantor Kelurahan Kebon Besar untuk mengetauhi tentang sistem pengolahan data penduduk maupun penerbitan suratsurat.

2. Wawancara (Interview)

Penulis melakukan wawancara untuk mengajukan beberapa pertanyaan kepada stakeholder yaitu Sekretaris Kelurahan Kebon Besar yang bernama Bapak Juanda mengenai sistem pengolahan data penduduk maupun penerbitan surat-surat yang berjalan saat ini.

3. Studi Pustaka

Metode yang dilakukan dengan melakukan proses studi pustaka dengan melihat referensi pendukung dengan dokumen-dokumen yang diperlukan. Sebagai bahan pertimbangan dalam pengambilan keputusan yang akan datang jika terdapat permasalahan yang sama.

\section{Metode Analisa}

Metode analisa yang digunakan dalam penelitian ini adalah Metode Analisa SWOT, yaitu Kekuatan (Strengths), Kelemahan (Weakness), Kesempatan (Opportunities), Ancaman (Threats). Analisis SWOT adalah suatu metode yang digunakan untuk melihat kondisi kantor Kelurahan baik internal maupun eksternal yang kemudian dijadikan indikator untuk mengetahui kekuatan, kelemahan, peluang, dan ancaman terhadap kantor Kelurahan, sehingga dapat membantu dalam pembuatan keputusan.

\section{Metode Perancangan}

Menurut Henderi dalam Saefudin dan Sri Lestari (2015:40), "UML adalah sebuah bahasa pemodelan yang telah menjadi standar dalam industri software untuk visualisasi, merancang, dan mendokumentasikan sistem perangkat lunak". Pada penelitian ini metode 
yang digunakan adalah UML (Unified Modeling Language) diantaranya yang menggunakan Use Case Diagram, Class Diagram, Sequence Diagram, Activity Diagram. Dengan menggunakan software Visual Paradigm for UML 13.0.

\section{Literature Review}

Menurut Warsito dkk (2015:29), "Metode studi pustaka dilakukan untuk menunjang metode survei dan observasi yang telah dilakukan. Pengumpulan informasi yang dibutuhkan dalam mencari referensi- referensi yang berhubungan dengan penelitian yang dilakukan". Berikut penelitian yang telah dilakukan dan memiliki korelasi yang searah dengan penelitian yang akan dibahas, antara lain :

1. Penelitian yang dilakukan oleh Nurrizky Bagus Setiawan dan Indah Uly Wardati pada penulisan karya ilmiahnya (Indonesian Journal on Networking and Security) yang berjudul "Perancangan Sistem Informasi Pencatatan Kelahiran Pada Dinas Kependudukan Dan Pencatatan Sipil Kabupaten Pacitan" tahun 2014 masalah yang dihadapi adalah Pada Dinas Kependudukan dan Pencatatan Sipil Kab. Pacitan, penulis menemukan suatu permasalahan pada proses pencatatan kelahiran karena masih dilakukan secara manual sehingga berdampak pada lamanya proses pencatatan. Bagaimana merancang sistem komputerisasi yang membantu proses pencatatan kelahiran. Tujuan dari kerja praktek ini adalah untuk merancang sistem informasi yang mempercepat proses pencatatan kelahiran Pada Dinas Kependudukan dan Pencatatan Sipil Kab. Pacitan. Dalam penelitian ini menguraikan tentang hal-hal apa saja yang menjadi faktor perancangan sistem informasi pencatatan kelahiran dan apa saja yang dibutuhkan dalam perancangannya. Yang dihasilkan dari penelitian dan perancangan sistem informasi pencatatan kelahiran ini adalah tersedianya beberapa informasi mengenai kelahiran seseorang dan mempermudah pelaksanaan sistem kerja pada Dinas Kependudukan dan Pencatatan Sipil Kab. Pacitan.

2. Penelitian yang dilakukan oleh Dwi Priyanti dan Siska Iriani pada penulisan karya ilmiahnya (Indonesian Journal on Networking and Security) yang berjudul "Sistem Informasi Data Penduduk Pada Desa Bogoharjo Kecamatan Ngadirojo Kabupaten Pacitan" tahun 2013 masalah yang dihadapi adalah saat ini Kantor desa Bogoharjo menggunakan sistem informasi secara konvensional yaitu pencatatan data penduduk pada sebuah buku induk yang disediakan oleh Desa, kemudian di rekap kembali untuk membuat laporan penduduk.Sistem yang berjalan mempunyai banyak kekurangan diantaranya memungkinkan adanya kesalahan, membutuhkan waktu yang lama dalam proses pencarian data, maupun dalam proses pembuatan laporan. Penelitian ini bertujuan untuk menghasilkan sebuah sistem informasi pengelolaan data penduduk yang lebih cepat, tepat guna, efektif dan efisien pada kantor Desa Bogoharjo.

3. Penelitian yang dilakukan oleh One Yunita Fujiyanti pada penulisan karya ilmiahnya (Journal Speed - Sentra Penelitian Engineering dan Edukasi) yang berjudul "Sistem Informasi Pengolahan Data Kependudukan di Desa Purwoasri" pada tahun 2013 masalah yang dihadapi adalah Kantor Desa Purwoasri merupakan sebuah lembaga instansi Pemerintahan Desa yang berada di Desa Purwoasri Kecamatan Kebonagung Kabupaten Pacitan. Kantor Desa Purwoasri melayani masyarakat dalam berbagai kebutuhan surat menyurat. Salah satunya adalah Pendataan data penduduk dan pengolahannya dalam bentuk laporan bulanan dan penerapannya ke dalam surat - surat leges. Namun dalam pelaksanaannya masih terjadi beberapa permasalahan. Permasalahan itu adalah masih sering terjadi kesalahan dalam mengolah atau mendata penduduk, Hal ini dikarenakan dalam pengolahanya masih dengan proses yang manual. Dalam penelitian ini akan dibahas tentang Sistem Informasi Pengolahan Data Kependudukan yang ada di Kantor Desa Purwoasri. Sehingga dengan adanya penelitian ini, nantinya akan mempermudah dalam memperbarui jumlah data penduduk dan dibuat laporannya. Selain itu juga data penduduk yang sudah ada akan diterapkan ke dalam surat- surat leges. Yang dalam penelitian ini akan diterapkan ke dalam salah satu surat leges.

4. Penelitian yang dilakukan oleh I Made Andi Pramartha pada penulisan karya ilmiahnya 
(Jurnal Elektronik Ilmu Komputer Universitas Udayana) yang berjudul "Implementasi Aplikasi SIG Dalam Pengolahan Data Jumlah Penduduk Berbasis Web" pada tahun 2012 masalah yang dihadapi adalah Banyaknya penduduk yang terdapat di Bali membuat beberapa penduduk sulit mengetahui jumlah penduduk yang terdapat di suatu daerah. Badan Pusat Statistik merupakan Badan yang bertugas untuk mencatat jumlah penduduk yang berada di setiap daerah. Salah satu upaya untuk memberikan informasi kepada masyarakat tentang banyaknya jumlah penduduk yang terdapat di Provinsi Bali adalah dengan membuat aplikasi yang dapat memberikan informasi kepada masyarakat. Peneliti merancang aplikasi berbasis web dengan menggunakan Google Maps API sebagai saran untuk aplikasi ini. Dan peneliti juga menggunakan bahasa pemrograman PHP dan MySQL. Aplikasi ini sudah dapat beroperasi sesuai dengan tujuan yaitu untuk mengetahui jumlah penduduk di setiap Kabupaten atau Kecamatan yang ada di Provinsi Bali.

5. Penelitian yang dilakukan oleh Dedi Prasetyo Nugroho pada penulisan karya ilmiahnya (Indonesian Journal on Networking and Security) yang berjudul "Perancangan Pendataan Kependudukan Desa Sugihwaras" tahun 2013 masalah yang dihadapi adalah Sistem informasi pendataan penduduk masih bersifat pembukuan atau secara manual. Cara sistem pembukuan tersebut akan sulit dalam proses pendataan penduduk. Permasalahan yang ada di Desa Sugihwaras, seperti sulitnya pemberian data dan informasi secara cepat dan akurat mengenai laporan pendataan penduduk dikarenakan banyaknya jumlah penduduk.

\section{Hasil dan Pembahasan}

Dalam penelitian ini menjelaskan tentang aplikasi sistem pengolahan data penduduk di era industri 4.0. Pembuatan sistem ini memiliki tujuan untuk dapat memberikan informasi surat - surat kependudukan agar terkomputerisasi dengan baik.

Rancangan sistem ini menggunakan Visual Paradigm for UML 13.0, salah satu nya menggambarkan use case diagram, activity diagram.

1. Use Case Diagram

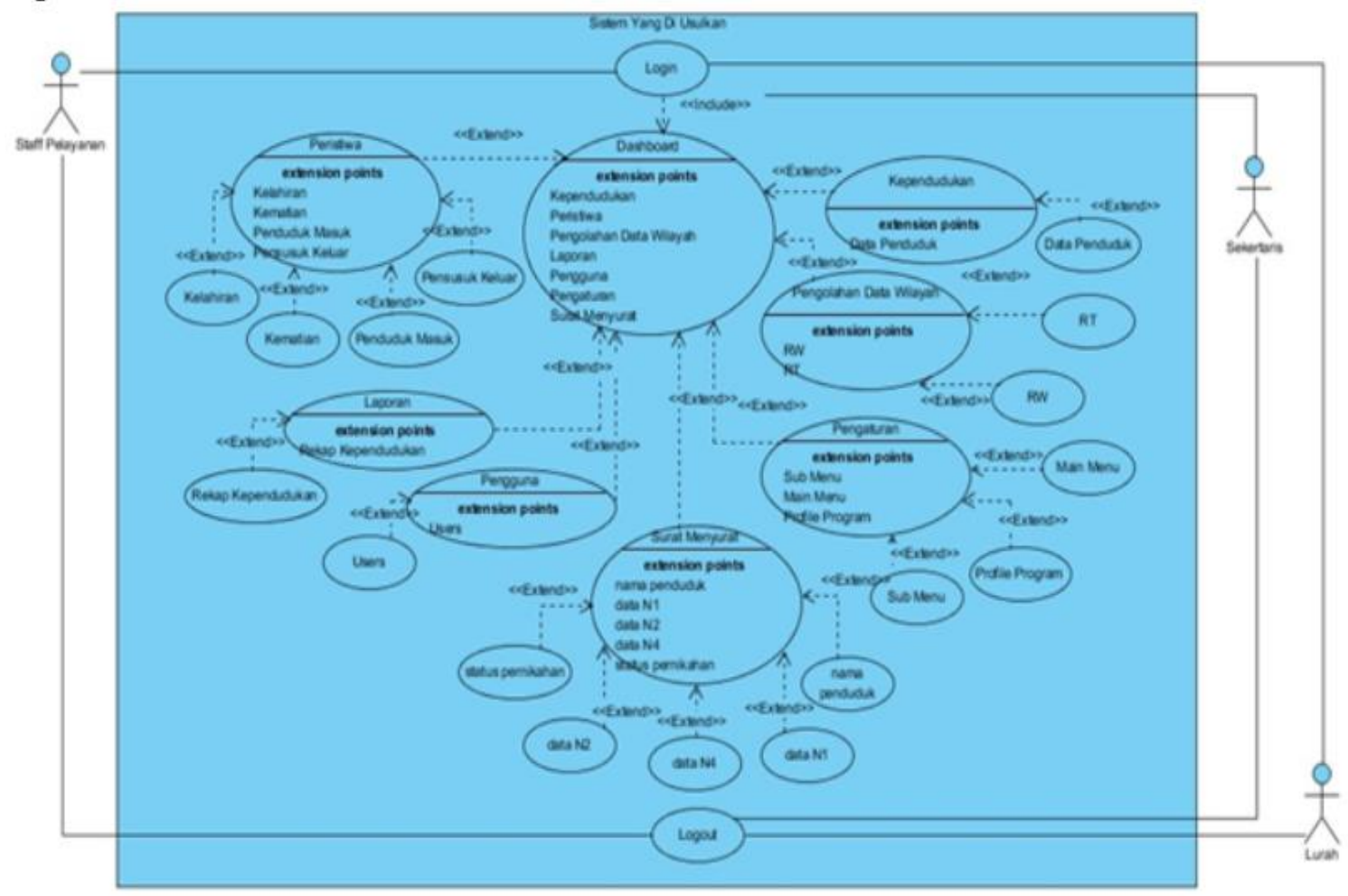

Gambar 1.1 Use Case Diagram 
Berdasarkan gambar use case diagram di atas, dapat diketahui :

1. Sistem boundary yang menggambarkan keseluruhan kegiatan dalam sistem informasi biaya yang berjalan saat ini.

2. Use case yang tergambar berjumlah 27 use case.

3. Tiga (3) aktor, yang melakukan kegiatan yaitu Staf Pelayanan, Sekretaris, Lurah.

2. Activity Diagram

a. Activity Diagram Staff Pelayanan

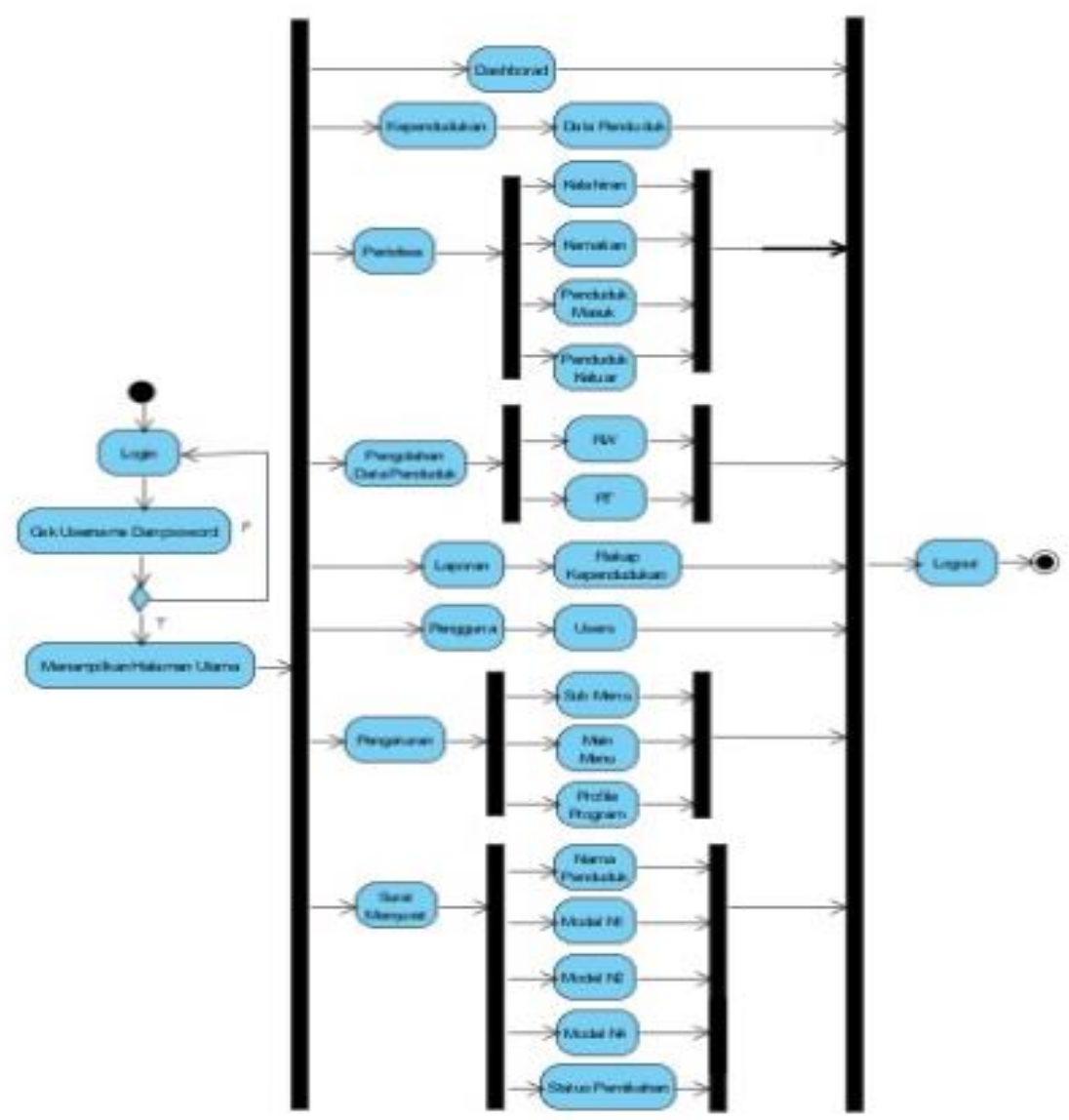

Gambar 1.2 Activity Diagram Staff Pelayanan

Berdasarkan gambar use case diagram di atas, dapat diketahui :

1. 1 initial node, merupakan node yang mengawali kegiatan.

2. 29 action state dari sistem yang mencerminkan eksekusi dari suatu aksi.

3. 1 decision node, yang mencerminkan sebagai pilihan eksekusi

4. 10 fork node, merupakan node yang membagi sebuah action state menjadi beberapa action state.

5. 1 final node, merupakan node yang mengakhiri kegiatan.

b. Activity Diagram Sekretaris 


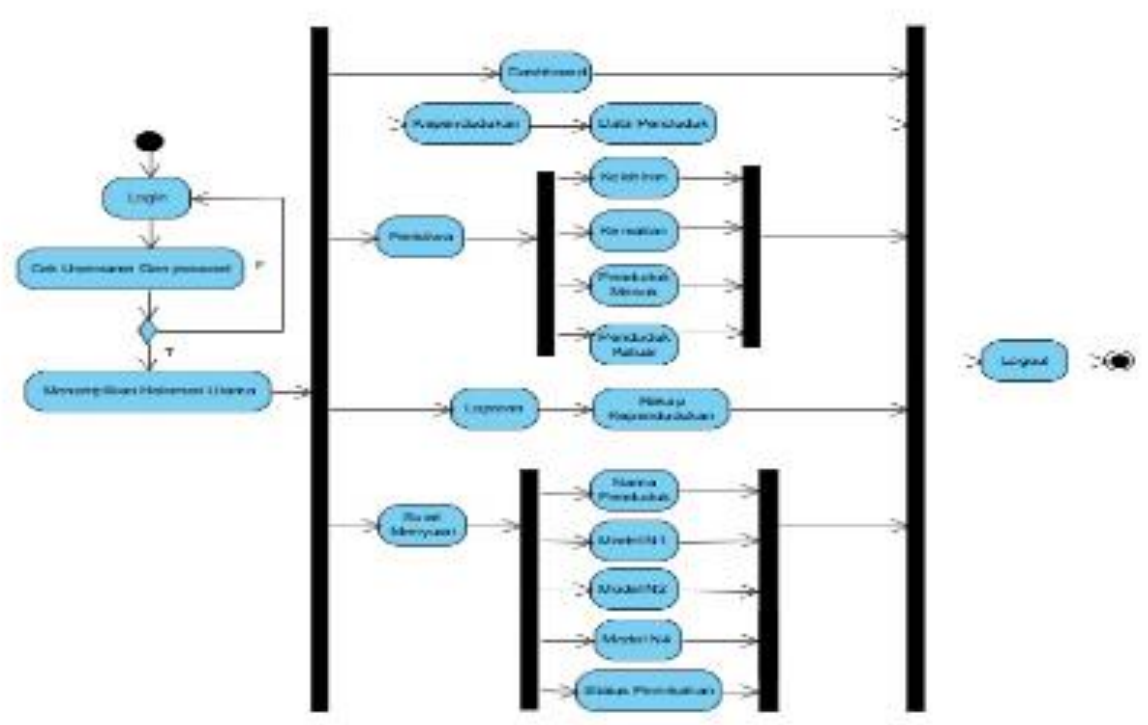

Gambar 1.3 Activity Diagram Sekretaris

Berdasarkan gambar use case diagram di atas, dapat diketahui :

1. 1 initial node, merupakan node yang mengawali kegiatan.

2. 20 action state dari sistem yang mencerminkan eksekusi dari suatu aksi.

3. 1 decision node, yang mencerminkan sebagai pilihan eksekusi

4. 6 fork node, merupakan node yang membagi sebuah action state menjadi beberapa action state.

5. 1 final node, merupakan node yang mengakhiri kegiatan.

c. Activity Diagram Lurah

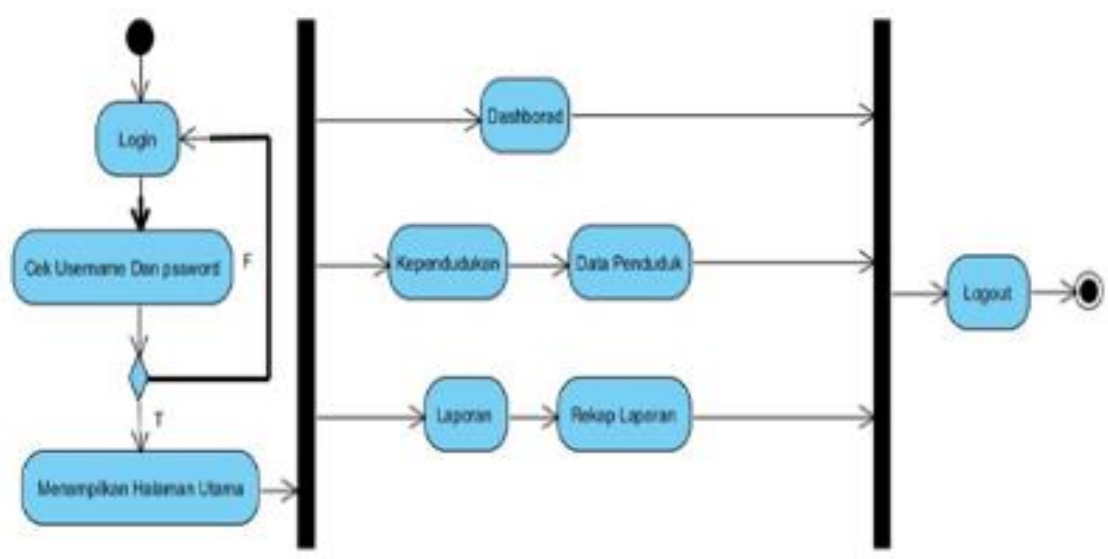

Gambar 1.4 Activity Diagram Lurah

Berdasarkan gambar use case diagram di atas, dapat diketahui :

1. 1 initial node, merupakan node yang mengawali kegiatan.

2. 9 action state dari sistem yang mencerminkan eksekusi dari suatu aksi.

3. 1 decision node, yang mencerminkan sebagai pilihan eksekusi

4. 2 fork node, merupakan node yang membagi sebuah action state menjadi beberapa action state.

5. 1 final node, merupakan node yang mengakhiri kegiatan. 


\section{Analisa Sistem Berjalan dan Sistem Usulan}

\begin{tabular}{|c|l|lr|}
\hline NO & \multicolumn{1}{|c|}{ Sistem Berjalan } & \multicolumn{2}{|c|}{ Sistem Usulan } \\
\hline 1. & $\begin{array}{l}\text { Sistem pengolahan data kependudukan } \\
\text { masih masih manual dengan mencatat } \\
\text { data warga menggunakan buku besar }\end{array}$ & $\begin{array}{l}\text { Sistem kependudukan } \\
\text { terkomputerisasi dengan } \\
\text { aplikasi web }\end{array}$ \\
\hline 2. & $\begin{array}{l}\text { Pelayanan masyarakat dalam } \\
\text { pembuatan permohonan surat - surat } \\
\text { masih manual }\end{array}$ & $\begin{array}{l}\text { Pelayanan masyarakat } \\
\text { pembuatan surat } \\
\text { terkomputerisasi dengan } \\
\text { aplikasi web }\end{array}$ & $\begin{array}{r}\text { dalam } \\
\text { adanya }\end{array}$ \\
\hline 3. & $\begin{array}{l}\text { Dalam pembuatan laporan } \\
\text { kependudukan membutuhkan waktu } \\
\text { lama dan data yang dihasilkan kurang } \\
\text { akurat }\end{array}$ & $\begin{array}{l}\text { Dalam pembuatan } \\
\text { kependudukan lebih menghemat waktu } \\
\text { dan data yang dihasilkan akurat }\end{array}$ \\
\hline
\end{tabular}

\section{Dibawah ini merupakan gambar tampilan rancangan yang dibuat :}

\section{Tampilan Login}

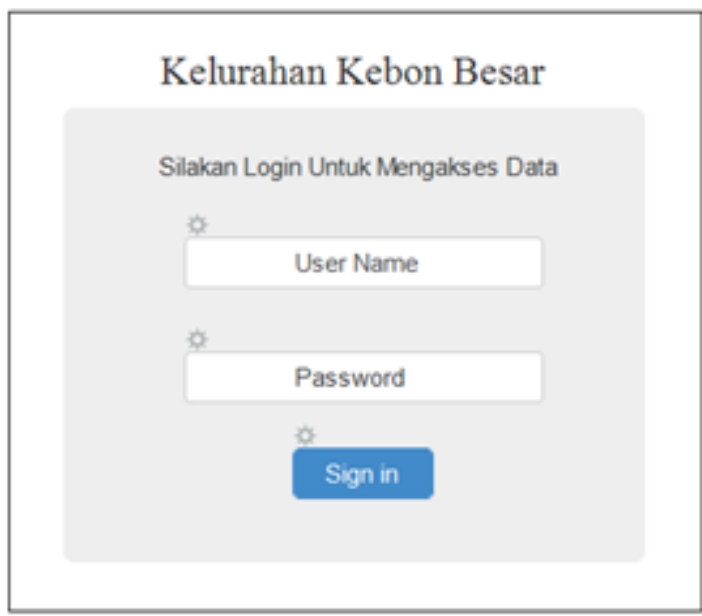

Gambar 2. Tampilan Login

Gambar 2 merupakan tampilan halaman login pada saat admin ingin akses. Halaman ini berfungsi untuk pengamanan agar tidak semua orang dapat mengakses nya. Pada menu login ini yang bisa login hanya admin atau yang bersangkutan.

\section{Tampilan Dashboard}




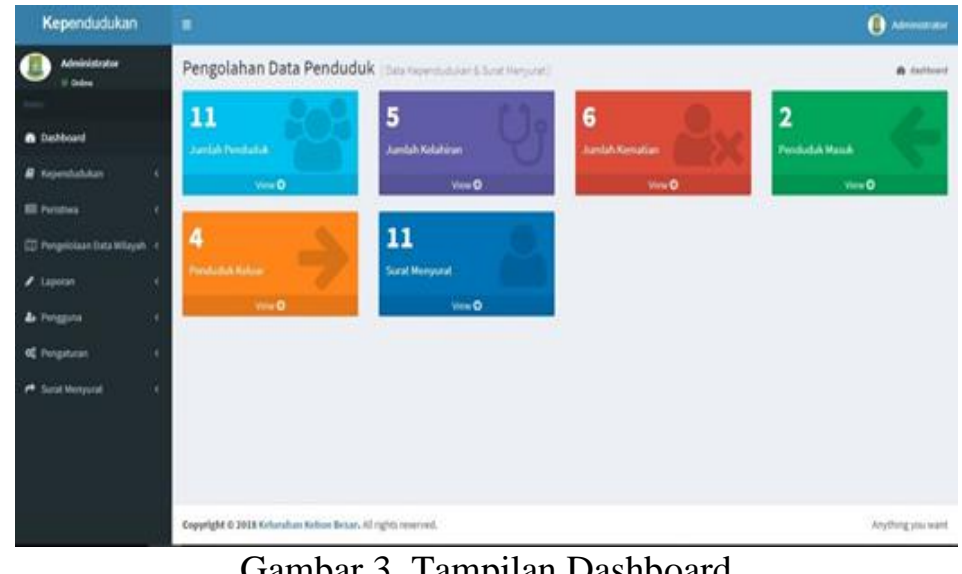

Gambar 3. Tampilan Dashboard

Gambar 3 merupakan halaman utama yang menyajikan menu-menu yang dapat diakses, dimana halaman ini muncul setelah admin berhasil memasukkan username dan password pada saat login.

\section{Tampilan Data Penduduk}

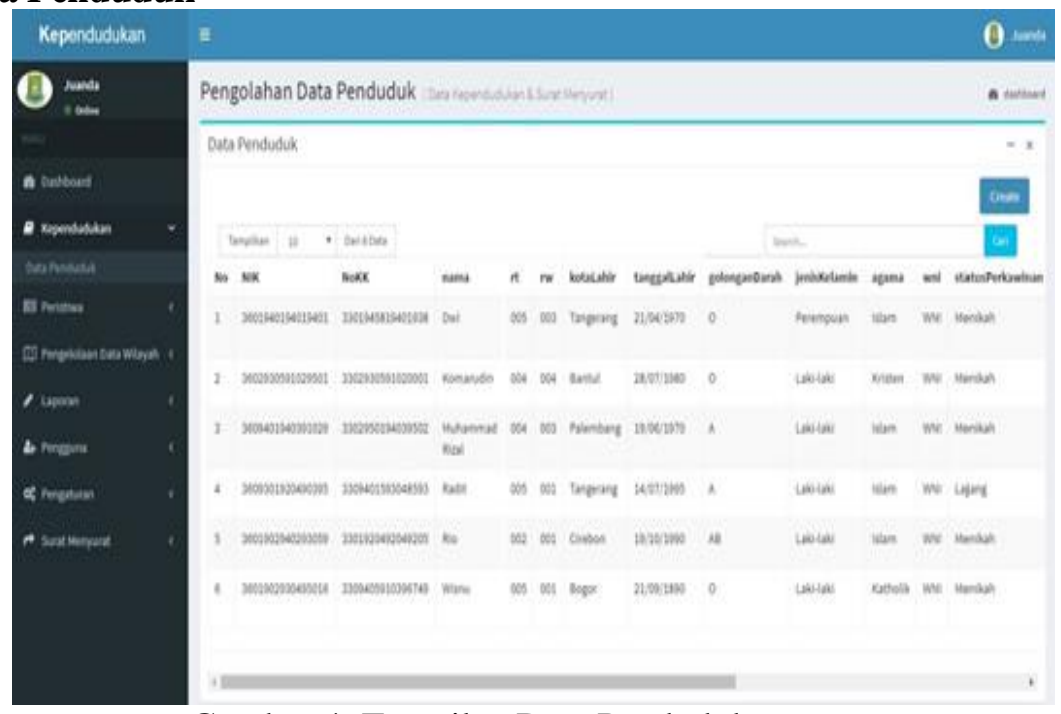

Gambar 4. Tampilan Data Penduduk

Gambar 4 merupakan halaman yang menampilkan data penduduk, dimana pada menu ini menampilkan secara keseluruhan tentang data kependudukan.

\section{Tampilan Data Penduduk Masuk}




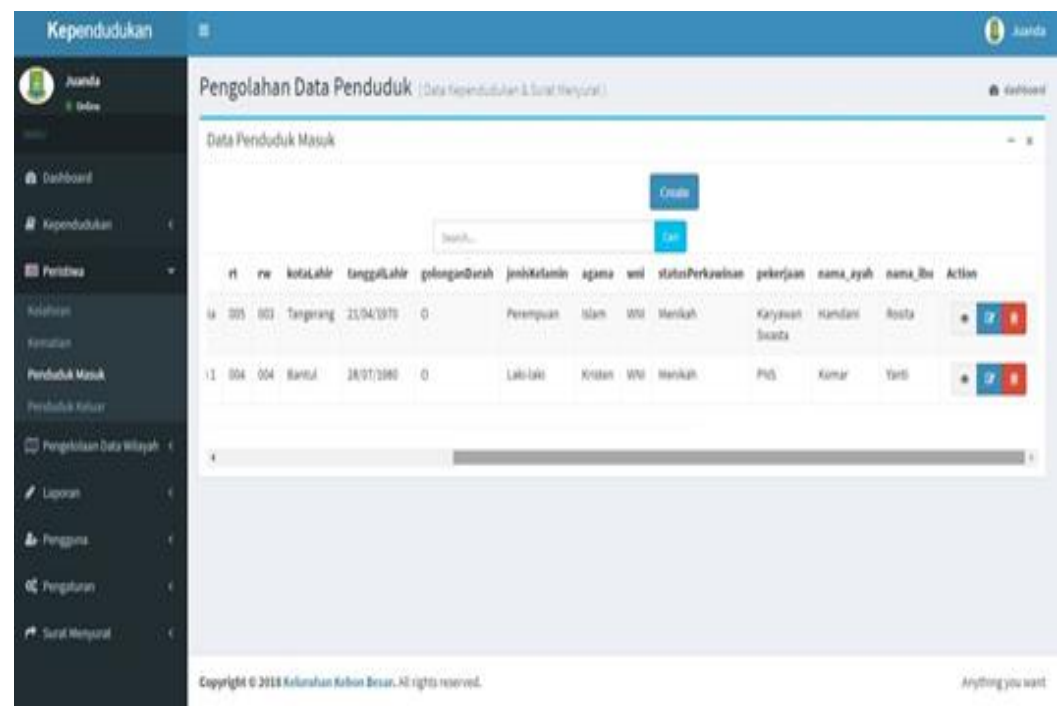

Gambar 5. Tampilan Data Penduduk Masuk

Gambar 5 merupakan halaman pengolahan data penduduk yang menampilkan data penduduk masuk.

\section{Tampilan Data Penduduk Keluar}

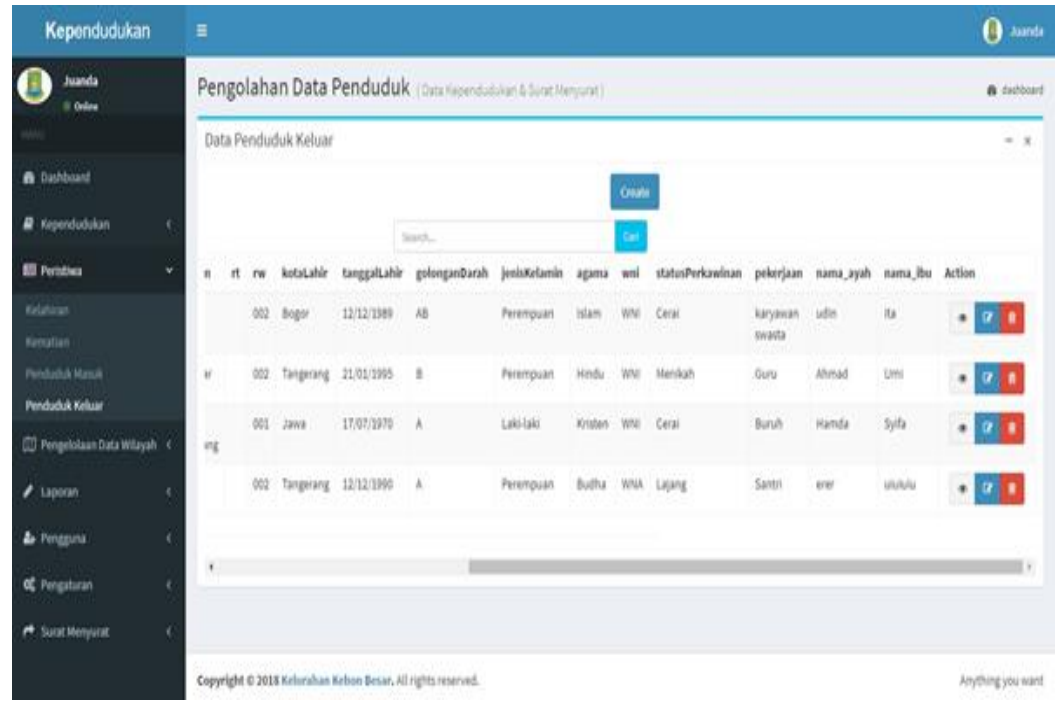

Gambar 6. Tampilan Data Penduduk Keluar

Gambar 6 merupakan halaman pengolahan data penduduk yang menampilkan data penduduk keluar.

\section{Kesimpulan}

Berdasarkan hasil penelitian yang dilakukan pada Sistem Pengolahan Data Penduduk pada Industri 4.0, maka penulis menarik kesimpulan sebagai berikut :

1. Proses pendataan penduduk dan pembuatan surat menyurat yang sedang berjalan saat ini pada Industri 4.0 masih berjalan secara semi komputerisasi yaitu proses pencatatannya masih menggunakan buku dan dicatat secara semi komputerisasi menggunakan Microsoft Excel dan pencarian data penduduk membutuhkan waktu yang lama.

2. Sistem yang berjalan saat ini belum mampu menghasilkan informasi yang dibutuhkan karena pengolahan datanya masih dilakukan secara manual dan penyimpanan dalam 
bentuk arsip sehingga masih sering terjadinya kesalahan dalam proses pendataan penduduk, pencarian data penduduk dan membutuhkan waktu yang lama untuk menghasilkan sebuah laporan.

3. Sistem informasi pengolahan data penduduk yang mampu menunjang kinerja (terkomputerisasi) sehingga data yang dihasilkan akurat, terperinci secara baik dan tidak membutuhkan waktu yang lama untuk mencari data penduduk.

\section{Saran}

Berdasarkan hasil penelitian dan analisis yang dilakukan oleh penulis mengenai Pengolahan Data Penduduk pada Industri 4.0, maka agar dapat dicapai hasil yang optimal dan juga bertujuan terhadap kelancaran dalam kegiatan pendataan dibutuhkan:

1. Perlu diadakan pelatihan kepada pengguna (user) yang akan menggunakan sistem tersebut sebagai administrator, agar dapat dimanfaatkan dengan baik.

2. Diperlukan back up data secara berkala dan perawatan untuk menghindari terjadinya kehilangan atau kerusakan data, agar kinerja sistem berjalan dengan baik dan sesuai harapan.

3. Sistem Informasi Pengolahan Data Penduduk yang diusulkan dirancang untuk Industri 4.0, untuk kedepannya dapat dikembangkan untuk wilayah Kecamatan/Kabupaten.

\section{Daftar Pustaka}

[1] Setyawan, N. B., \& Wardati, I. U. (2013). Perancangan Sistem Informasi Pencatatan Kelahiran Pada Dinas Kependudukan Dan Pencatatan Sipil Kabupaten Pacitan. IJNSIndonesian Journal on Networking and Security, 3(2).

[2] Priyanti, D., \& Iriani, S. (2013). Sistem Informasi Data Penduduk Pada Desa Bogoharjo Kecamatan Ngadirojo Kabupaten Pacitan. IJNS-Indonesian Journal on Networking and Security, 2(4).

[3] Fujiyati, O. Y. (2013). Sistem Informasi Pengolahan Data Kependudukan Di Desa Purwoasri. Speed-Sentra Penelitian Engineering dan Edukasi, 7(1).

[4] Pramartha, I. M. A. (2012). Implementasi Aplikasi Sig Dalam Pengolahan Data Jumlah Penduduk Berbasis Web. Jurnal Elektronik Ilmu Komputer, 1(2), 87-91.

[5] Prasetyo, H., \& Sutopo, W. (2018). Industri 4.0: Telaah Klasifikasi aspek dan arah perkembangan riset. J@ ti Undip: Jurnal Teknik Industri, 13(1), 17-26.

[6] Nugroho, D. P. (2013). Perancangan Pendataan Kependudukan Desa Sugihwaras. IJNSIndonesian Journal on Networking and Security, 4(3).

[7] Warsito, A. B., Yusup, M., \& Makaram, M. I. A. (2015). Perancangan SIS+ Menggunakan Metode YII Framework Pada Perguruan Tinggi Raharja. CCIT Journal, $8(2), 24-33$.

[8] Saefudin, S., \& Lestari, S. (2017). Sistem Pendukung Keputusan Untuk Penilaian Kinerja Karyawan PT. Mulia Spindo Mills Menggunakan Metode Algoritma C4. 5. ProTekInfo (Pengembangan Riset dan Observasi Teknik Informatika), 2, 40-43.

[9] Satya, V. E. (2018). Strategi Indonesia Menghadapi Industri 4.0. INFO Singkat.

[10] Dalimunte, R. P., Paramita, H., \& Adilla, S. (2018). Tantangan Komunikasi Baru Digital 
dan Revolusi Industri 4.0. Prosiding Konferensi Nasional Komunikasi, 2(01), 789-794.

[11] McLeod, R., \& Schell, G. (2004). Sistem informasi manajemen. Indeks.

[12] Tulodo, B. A. R., \& Solichin, A. (2019). ANALISIS PENGARUH KUALITAS SISTEM, KUALITAS INFORMASI DAN PERCEIVED USEFULNESS TERHADAP KEPUASAN PENGGUNA APLIKASI CARE DALAM UPAYA PENINGKATAN KINERJA KARYAWAN. JRMSI-Jurnal Riset Manajemen Sains Indonesia, 10(1), 25-43.

[13] PUTRI, E. S., Wirawan, I. M. A., Kom, S., Cs, M., \& Divayana, D. G. H. (2019). PENGEMBANGAN SISTEM PENDUKUNG KEPUTUSAN BAGI DOKTER KELUARGA DALAM MENDIAGNOSA PENYAKIT DENGAN METODE DEMPSTER-SHAFER. Kumpulan Artikel Mahasiswa Pendidikan Teknik Informatika (ISSN: 2252-9063), 8(1).

[14] Suwardana, H. (2018). Revolusi Industri 4. 0 Berbasis Revolusi Mental. JATI UNIK: Jurnal Ilmiah Teknik dan Manajemen Industri, 1(2), 102-110.

[15] Taufiq, R. (2019). RANCANG BANGUN SISTEM PENDUKUNG KEPUTUSAN PENENTUAN JUMLAH PRODUKSI MENGGUNAKAN METODE FUZZY TSUKAMOTO. Jurnal Teknik, 8(1). 